\title{
Recent advances in (S)TEM and related spectroscopies: a tribute to $\mathrm{C}$. Colliex
}

This special issue of Eur. Phys. J. Appl. Phys. is dedicated to Christian Colliex's work, more particularly his outstanding contribution to electron energy-loss spectroscopy (EELS) and STEM imaging.

Since his inception in the 1960s, when these methods were nothing more than laboratory curiosities, Christian has been a constant driving force, pushing them to the forefront in the world of micro- and nano-analytical science. He is one of the key people who contributed to turn EELS, a difficult specialist technique mainly of interest to hardcore physicists, into a mainstream tool for analytical transmission electron microscopy. While encompassing many aspects of EELS, improving the understanding of the physical principles to extract all the richness of the underlying information has been the main thread along all his work. His willingness to consider the practical difficulties and clear results presentation in over 300 major publications have significantly contributed to the present ease and power of the technique.

His early feeling being that getting ultimate performances would only be possible with expensive instruments supported by sound teams, Christian started some 10 years ago to gather leading TEM laboratories in an international project that led eventually to the ESTEEM net which is coordinated by the EMAT center (Antwerpen University) and offers the best capabilities to the whole European microscopist community. He also used his talents as communicator and manager as Director of the Aimé Cotton Laboratory in Orsay (1996-2001), President of the French Society of Electron Microscopy SF $\mu$ (1990-1991), and President of the International Federation of the Society of Microscopy IFSM (2006-2010), and currently Vice-President.

The idea of dedicating a special issue to Christian Colliex became obvious while preparing the conference "Past, present and future of (S)TEM and its application, a tribute to Christian Colliex work", which took place in Paris in May 2010. The conference was featuring eminent speakers from diverse backgrounds who presented the historical developments and the challenges for the future across the many domains to which Christian has contributed. Pushed by the $\mathrm{SF} \mu$, the idea of gathering the contributions of most of the speakers together with those of distinguished scientists whose experience widens the conference field led to this special issue.

We are very indebted to the speakers and invited scientists who agreed to contribute. We would like to deeply thank them for the high quality of their manuscript in spite of the short deadline.

This issue is aimed at a broad readership of physicists, materials scientists and microscopists from both inert and biological matter. It features articles dealing with new advances in instrumentation, analysis, modeling and interpretation as well as recent applications. In particular three major improvements of resolution are addressed in this issue: the gain of spatial resolution that occurred during the last few years, the energy resolution in electron spectroscopies being implemented now and the time resolution with the first time-resolved EELS observations beyond the picosecond and their physical interpretation.

The choice of Eur. Phys. J. Appl. Phys. was obvious since Christian was one of its founding editors. We would like to thank EDP Sciences and the SF $\mu$, whose support makes this issue available online in Open Access to all readers. We strongly believe this will help to widespread the science of electron microscopy and spectroscopy knowledge in the way Christian always loved to: high standard but always accessible. 